\title{
Exploring global citizenship as a cross-curricular theme in Moroccan ELT textbooks
}

\author{
Hassan Ait-Bouzid a * \\ a Ibn Zohr University, Department of English Studies, Agadir 80000, Morocco
}

\begin{tabular}{l|l|l} 
Received 23 July 2019 & Received in revised form 22 January 2020 & Accepted 25 March 2020
\end{tabular}

\section{APA Citation:}

Ait-Bouzid, H. (2020). Exploring global citizenship as a cross-curricular theme in Moroccan ELT textbooks. Eurasian Journal of Applied Linguistics, 6(2), 229-242.

Doi: 10.32601/ejal.775801

\begin{abstract}
This paper examines ways in which three Moroccan ELT textbooks currently used in teaching second year Baccalaureate students in public high schools promote values of global citizenship. It also investigates the extent to which these textbooks present activities that develop learners' sense of belonging to global and local communities and provide them with skills, knowledges and behaviors that would make them good citizens of the world. The study uses the theoretical framework of the StandardsBased Approach and UNESCO's (2015) global citizenship learning domains. It adopts a convergent parallel mixed-methods design and uses content analysis as a data analysis method which combines both qualitative and quantitative techniques. The data are collected using a checklist that is designed based on UNESCO's framework. The materials include three textbooks: Gateway to English 2, Insights into English 2 and Ticket to English 2. The findings demonstrate that although the three textbooks actually provide a number of activities that promote aspects of citizenship, there is still room for improving learners' awareness of various global issues including democracy, human rights and conflict resolution. Other problems related to developing learners' critical perspective towards global citizenship themes in reading texts, speaking, listening and writing activities and project works were identified. The study concludes with implications that inform teachers and textbook designers about the importance of empowering values of global citizenship in ways that strengthen learners' critical thinking and problemsolving skills.

(C) 2020 EJAL \& the Authors. Published by Eurasian Journal of Applied Linguistics (EJAL). This is an open-access article distributed under the terms and conditions of the Creative Commons Attribution license (CC BY-NC-ND) (http://creativecommons.org/licenses/by-nc-nd/4.0/).
\end{abstract}

Keywords: ELT; global citizenship; Moroccan high school; SBA; textbook evaluation.

\section{Introduction}

\subsection{Statement of the problem}

In today's globalized world, the unlimited mobility of people, goods and ideas would presumably result in various modes of conflicts, misunderstandings and inequalities if global citizenship values were not cultivated among world citizens. What a better

\footnotetext{
* Corresponding author. Tel.: +212668989269

E-mail address: h.aitbouzid@uiz.ac.ma http://dx.doi.org/10.32601/ejal.775801
} 
means to disseminate and reinforce these global values across the globe than English, the official language of globalization. The international dimension of English has made it a perfect vehicle capable of fostering the awareness of its users towards global issues. In this regard, one of the main purposes of teaching English as a foreign language at an international scale is to provide an opportunity to teach, learn and develop values of global citizenship (Oxfam, 2015). The main reason why EFL promotes global citizenship is that the EFL classroom is one of the rare educational settings where non-English speaking learners interact with foreign cultures that transport global perspectives, practices and products. The EFL classroom is often considered a contact zone where local and foreign cultures interact, offering learners opportunities to recognize, compare, contrast and understand similarities and differences of various local, national and international viewpoints towards glocal issues. In such settings, learners eventually "realize the interdependence of people throughout the world" (American Council on the Teaching of Foreign Languages [ACTFL], 2001, p. 63). Thus, developing an understanding of different worldviews raises the awareness of learners to what global citizenship is and what kind of knowledges, values, skills and behaviors global citizens are expected to demonstrate. In short, the cross-cultural nature of ELT classroom makes it the most suitable for teaching and learning global citizenship (Diaz, 2017; Guilherme, 2002).

Promoting awareness of global citizenship is a key objective of foreign language learning (Byram, 2003; Weninger \& Kiss, 2013), more specifically in an increasingly globalized world where questions about the meaning and value of citizenship are being raised. In EFL contexts like Morocco, English language teaching is expected to instill and develop the essential skills, knowledges and behaviors that learners need "to grow as effective world citizens; able to transmit, share and compare ideas, information and cultural patterns of different speakers" (Ministry of National Education [henceforth MNE], 2007, p.17). It is also important that English language teaching in Morocco fosters learners' connection with their communities at the local, national and global levels through developing their awareness of their responsibilities and rights in order to grow autonomous and responsible citizens (MNE, 2007). To this end, the various elements which shape the teaching-learning process should be designed with the aim of promoting the achievement of the global citizenship objective. Accordingly, ELT textbooks, major elements of the teaching-learning process, are expected to facilitate the attainment of such an objective.

Textbooks are instrumental materials that facilitate the teaching learning process. They are viewed as essential tools which present, organize and illustrate the curriculum. However, textbooks are generally imperfect as they may contain problems related to the selection, presentation and organization of their social, cultural, linguistic and pedagogical contents. These imperfections can only be identified and improved through the practice of textbook evaluation. Research maintains that systematic, reflective and in-depth textbook evaluation serves to a great extent the improvement of the quality of textbooks (Ait Bouzid, Erguig, \& Yeou, 2016, Cunningsworth, 1995; Litz, 2005). 


\subsection{Theoretical framework}

In the present study, textbook evaluation is used as a means to examine the extent to which three Moroccan ELT textbooks currently used in teaching 2nd year Baccalaureate students in public schools provide learners with activities that promote values of global citizenship. To this end, the study is situated within, first, the theoretical framework of the Standards-Based Approach, which currently guides the teaching and learning of English a foreign language in Morocco, with particular reference to the goal areas of Cultures and Communities and, second, the UNESCO's Global Citizenship Education framework (2015). The ultimate objective of the Standards-Based Approach is to equip learners with knowledges, skills and behaviors that enable them to effectively function in a multi-cultural global community of English language speakers while at the same time maintaining their local identity as foreign language speakers. While the goal area of Cultures fosters values of intercultural understanding by helping learners establish a constructive comprehension of similarities and differences between local, national and global cultures, the goal area of Communities encourages learners to engage actively in actions that can raise their awareness of the interconnectedness of local, national and global issues and eventually drawing their attention to how individual local actions can eventually influence global issues (ACTFL, 1995; MNE, 2007)..

The study is equally informed by UNESCO's (2015) framework of global citizenship education. In this regard, UNESCO's framework identifies three dimensions of citizenship which in turn form three domains of global citizenship education, namely the cognitive, socio-emotional and behavioural domains of learning. The cognitive domain of learning aims to equip learners' with knowledges and critical thinking skills that will enable them to understand how global regional, national and local issues reinforce the interconnectedness and interdependency of different countries and populations. The Socio-emotional domain of learning encourages learners to have a sense of belonging to a common humanity, sharing values and responsibilities, empathy, solidarity and respect for differences and diversity. The Behavioral domain of learning enables learners to act effectively and responsibly at local, national and global levels for a more peaceful and sustainable world. These domains are developed into sub-topics that aim to achieve a number of learning objectives which are presented gradually into four developmental consecutive levels ranging from perprimary, upper-primary, lower-secondary to upper-secondary levels. In this study, we are only concerned with subtopics and learning objectives relevant to the uppersecondary level which matches the age-category of Moroccan 2nd year Baccalaureate students.

This framework offers insights into basic elements that constitute the contents and objectives of global citizenship education. It is therefore suitable for the textbook evaluation this study aims to conduct. The framework provides basic theoretical foundations for, first, identifying activities that target the promotion of global citizenship values and, second, classifying these activities within the three domains of 
learning in accordance with the themes they discuss and the objectives they intend to meet.

\subsection{Literature review}

Research maintains that EFL curricula are characterized by a significant degree of flexibility which provides sufficient room for integrating global citizenship education as a cross-curricular theme (Basarir, 2017; Cates, 2009). However, it is noticed that EFL textbooks provide nothing but an uneven, informative and superficial overview of global citizenship (De La Caba, 2013). Similarly, Zhu (2013) observed that citizenship values presented in EFL textbooks usually tend to promote more national dimensions than local and global ones especially when the textbooks are administered by national authorities, and when they are designed to serve as teaching materials within national curricula. Basarir (2017) and Erfani (2012) claim that EFL textbooks currently used in Iran do not provide enough contents that raise learners' awareness to global issues such as environmental issues, socio-economic issues, world-peace issues, intercultural understanding issues, human rights issues, global health issues and linguistic imperialism.

The situation in UK, USA, Canada and New Zealand is slightly different. According to Kerr (1999), Pederson and Cogan (2002) and O'Brien and Parry (2002), global citizenship education has been introduced to schools as a compulsory crosscurricular theme in the beginning of the $21^{\text {st }}$ century. De La Caba and Atxurra (2006) identify human rights, conflict resolution, democracy, responsibility and diversity as popular themes around which Spanish primary school textbooks build discussions of citizenship. Nevertheless, the researchers note that these textbooks present forms of bias concerning the number and the diversity of contexts and perspectives they illustrate.

In the Moroccan context, few studies have tackled the issue of global citizenship education as a cross-curricular theme. Life Skills and Citizenship Education [LSCE] (2017) reports that citizenship education is still in its initial stage in the MENA region. It also observes that this topic has not yet acquired its global dimension as it is mainly concerned with national and social issues. To improve the situation, LSCE suggests developing new learning contents and tools that would promote a better integration of global citizenship education among adolescents in formal education. LSCE (2017, p. vi) describes Morocco as a model for best practices of promoting peace and global citizenship through religious education. In the same token, Ait Bouzid (2016) presents an analysis of the extent to which Moroccan ELT textbooks provide contents that promote religious tolerance, peaceful coexistence, respect for difference among people of both foreign and local cultures. Findings indicate that such contents are scarce in the three textbooks that were examined. Similarly, El Karfa (2007) investigates whether EFL classes provide learners with knowledges, values and skills to prepare them to become effective citizens. The study also discusses the selection of contents and activities that promote civic education among Moroccan EFL learners. 
The researcher suggests learner-centered activities including problem-solving activities, group work, role-plays, simulations, opinion-gap activities and informationgap activities as techniques for promoting learners' civic engagement.

A common trait of the two above mentioned studies conducted in the Moroccan context is their focus on national citizenship at the expense of global citizenship. Also, it is found that they stress the role of teachers, learners, policy-makers and overlook the role of the teaching material, namely the textbook, which commonly presents, organizes and illustrates the content to be taught. It is also noted that these studies do not tackle the issue of global citizenship in its totality; they merely investigate subtraits of global citizenship including national citizenship, values of tolerance, peace, coexistence and diversity. Other aspects including the local and the international dimensions of citizenship, themes, skills and behaviors are to a great extent left undiscussed.

The present study is different from previous studies in the Moroccan context in three ways. To start with, while the above stated studies consider global citizenship as a secondary theme in their analysis, the present one makes global citizenship its focal point as it is concerned with investigating, analyzing and discussing themes, knowledges, skills and values of global citizenship. The second distinction is that the present study examines the presentation of global citizenship in Moroccan EFL textbooks within two main theoretical frameworks, one of which (UNESCO's) is specifically designed for measuring the effectiveness of global citizenship education. The third difference is related to the rationale of the study since this one particularly addresses textbook designers and draws their attention to the importance of incorporating activities that promote different domains of global citizenship in future Moroccan ELT textbooks. Thus, the present study is to a great extent different from previous ones with regard to its scope, content and rationale.

\subsection{Objectives and research questions}

In light of the previous studies, the present study aims to develop a more general analysis of global citizenship. It sheds light on how the three dimensions of citizenship (local, national and global) interact within Moroccan ELT textbooks with more focus on identifying the global citizenship skills, knowledges, values and behaviors which are promoted through these textbooks. The study also examines the amount and types of activities and themes that are used to develop learners' awareness of global citizenship issues.

In this regard, this paper aims to explore the extent to which Moroccan ELT textbooks currently used in teaching $2^{\text {nd }}$ year Baccalaureate promote values of global citizenship. It also examines the nature and types of activities that are promote global citizenship values with regard to selection, organization and presentation. The present paper hopes to draw the attention of ELT practitioners to the viability of using the ELT textbook as a means to reinforce global citizenship education and 
eventually suggest ways in which future textbooks can help students become global citizens. To this end, this study addresses two main research questions:

1. To what extent do $2^{\text {nd }}$ year Baccalaureate textbooks provide activities that promote cognitive, socio-emotional and behavioral domains of global citizenship?

2. What kind of activities and themes do these textbooks use to promote cognitive, socio-emotional and behavioral domains of global citizenship?

\section{Method}

\subsection{Design}

To answer these questions, the present study adopts a convergent parallel mixedmethods design. This design allows the simultaneous collection of both quantitative and qualitative techniques and facilitates cross-comparing the quantitative and qualitative findings to build a comprehensive understanding of the representation of global citizenship in Moroccan ELT textbooks. The rationale for a convergent parallel mixed-methods design "is that one data collection form supplies strengths to offset the weaknesses of the other form, and that a more complete understanding of a research problem results from collecting both quantitative and qualitative data" (Creswell, 2012: 540). It is a one-phase design that allows for collecting the qualitative and quantitative data concurrently, analyzing the two datasets separately, comparing the results and interpreting them to identify whether they support or contradict one another. The strong point of this design is that the two data sets complement and compensate for each other's weaknesses allowing the researcher "to gather information that uses the best features of both quantitative and qualitative data collection" (p. 541). While the quantitative data allows for generalizing the findings, the qualitative data provide information about their context and setting.

\subsection{Procedures}

Initially, the procedures of data collection and analysis start with the qualitative identification of themes of activities included in the textbooks. This qualitative process is based on identifying whether activities present a central theme that is directly related to global citizenship. Accordingly, reading comprehension texts, exercises, dialogues, grammar and vocabulary exercises, writing activities and project-work activities are scanned to identify themes that are related to global citizenship. Conventionally, global citizenship themes include: global citizenship, citizenship, environmental issues, role of NGOs, cross-cultural dialogue, immigration, brain drain, unemployment, poverty, racial and ethnic diversity, conflict resolution, democracy, religious tolerance, social and political activism, youth engagement, voluntary work, human rights, global health, legal and constitutional issues, gender issues and economic issues. Any activity that tackles one of these themes is counted and classified according to the quantitative procedures explained below. 
After identifying activities that discuss global citizenship issues, they are immediately counted and classified according to whether they aim to promote the cognitive, the socio-emotional or the behavioral domains of learning. To perform this procedure, a checklist is developed based on the UNESCO framework. The purpose of the checklist is to reinforce the inter-coder reliability and facilitate the process of making frequency counts that measure frequency of occurrence of contents that are related to global citizenship. In accordance with UNESCO (2015), the checklist is divided into two levels. The first level includes three sections that represent the three global citizenship domains of learning. The first section of the checklist includes the cognitive domain in which are counted all activities whose aim is to provide learners with knowledge and information about how local, national and international issues are interconnected. The second section of the checklist is about the socio-emotional domain where activities that promote learners' sense of belonging to a global community and empathy towards humanity are classified. The third section of the checklist presents the behavioral domain which includes frequency counts of all activities that encourage learners to plan and take action at local, national and global levels towards a more sustainable world. The results of this analysis are shown in the form of frequency counts and percentages in Table 1. A chi-square statistic was calculated to examine whether the results of the frequency counts are statistically significant.

On a second level of the checklist, each section of a learning domain is further divided into three subsections that include Topics. These topics allow for a succinct identification and classification of the activities included in the textbooks according to the nature of their content. Consequently, the activities of the Cognitive domain of learning are further examined to identify whether they discuss topics of (1) local, national and global system structures, (2) local, national and global community issues or (3) power dynamics. Similarly, the activities of the socio-emotional domain of learning are further classified within topics of (1) different levels of identify, (2) belonging to different communities and (3) respect for difference and diversity. Activities belonging to the behavioral domain of learning are categorized into (1) actions taken individually or collectively, (2) ethically responsible behaviors and (3) getting engaged and taking action. The results of this analysis are presented in terms of frequency counts and percentages illustrated in Table 2. A chi-square statistic could not be calculated to examine whether the results of the frequency counts are statistically significant because some of the values of the frequencies are below

\subsection{Materials}

This study aims to evaluate the content of three Moroccan ELT textbooks currently used in teaching second year Baccalaureate students in public schools, namely Gateway to English 2 (Hassim, Blibil, \& Rasmy, 2007), Insights into English 2 (Najbi \& El Haddad, 2007) and Ticket to English 2 (Hammani, Ahssen, \& Tansaoui, 2007). These textbooks contain ten units that are presented in different orders. These units include several themes which have direct links to global citizenship such as 
citizenship, international organizations, sustainable development, brain drain and culture. The choice of these textbooks is based on a general assumption that students at their final year in high school need to be equipped with basic knowledges, skills and behavior that will enable them to become active global citizens. Therefore, they are expected to present contents that facilitate the task of teaching and learning global citizenship values for both teachers and students.

\section{Results}

Table 1 offers a statistical representation of the number of activities that promote cognitive, socio-emotional and behavioral learning domains within each of the three textbooks.

Table 1. Number of activities promoting different global citizenship's learning domains

\begin{tabular}{|c|c|c|c|c|c|c|c|c|}
\hline \multirow{2}{*}{$\begin{array}{l}\text { Domain } \\
\text { Cognitive }\end{array}$} & \multicolumn{2}{|c|}{ Gateway 2} & \multicolumn{2}{|c|}{ Insights 2} & \multicolumn{2}{|c|}{ Ticket 2} & \multicolumn{2}{|c|}{ Total } \\
\hline & 19 & $35.8 \%$ & 14 & $27.5 \%$ & 13 & $25 \%$ & 46 & $29.5 \%$ \\
\hline Socio-emotional & 23 & $43.4 \%$ & 28 & $54.9 \%$ & 25 & $48 \%$ & 76 & $48.7 \%$ \\
\hline Behavioral & 11 & $20.8 \%$ & 9 & $17.6 \%$ & 14 & $27 \%$ & 34 & $21.8 \%$ \\
\hline TOTAL & 53 & $100 \%$ & 51 & $100 \%$ & 52 & $100 \%$ & 156 & $100 \%$ \\
\hline
\end{tabular}

Table 1 shows that the three textbooks contain a total of 156 activities that promote global citizenship. It is observed that there is no big difference among the three textbooks in terms of the number of activities they include as they contain approximately the same number: 53 in Gateway to English 2, 52 in Ticket to English 2 and 51 in Insights into English 2. However, the discrepancy is seen in the distribution of activities among the three learning domains. In this regard, it is observed that activities promoting socio-economic domains dominate $(48.7 \%)$ over those promoting both the cognitive domain (29.5\%) and the behavioral domain (21.8\%).

A chi-square statistic is calculated to examine whether the frequencies and percentages illustrated in Table 1 are statistically significant. The results of the chisquare test are illustrated in Table 2 which compares the observed values $(\mathrm{O})$ to the expected values $(\mathrm{E})$ and calculates the chi-square statistics of each $\left(\mathrm{X}^{2}\right)$. The test is found to be statistically insignificant as the chi-square statistic is 2.9234 . The p-value is .570723. Thus, the results are not significant at $\mathrm{p}<.05$. The results in Table 2 therefore suggest that there is no significant difference among the three textbooks in terms of the number of activities that promote the cognitive, socio-emotional and behavioral global citizenship domains of learning.

Table 2: Chi-square test results

\begin{tabular}{|c|c|c|c|c|c|c|c|c|c|c|}
\hline \multirow[b]{2}{*}{ Domain } & \multicolumn{3}{|c|}{ Gateway 2} & \multicolumn{3}{|c|}{ Insight 2} & \multicolumn{3}{|c|}{ Ticket 2} & \multirow[b]{2}{*}{ Total } \\
\hline & $\mathrm{O}$ & $\mathrm{E}$ & $\mathrm{X}^{2}$ & $\mathrm{O}$ & $\mathrm{E}$ & $\mathrm{X}^{2}$ & $\mathrm{O}$ & $\mathrm{E}$ & $\mathrm{X}^{2}$ & \\
\hline Cognitive & 19 & 15.63 & 0.73 & 14 & 15.04 & 0.07 & 13 & 15.33 & 0.36 & 46 \\
\hline $\begin{array}{l}\text { Socio- } \\
\text { Emotional }\end{array}$ & 23 & 25.82 & 0.31 & 28 & 24.85 & 0.40 & 25 & 25.33 & 0.00 & 76 \\
\hline
\end{tabular}




\begin{tabular}{lllllllllll}
\hline Behavioral & 11 & 11.55 & 0.03 & 9 & 11.12 & 0.40 & 14 & 11.33 & 0.63 & 34 \\
Total & 53 & & & 51 & & & 52 & & & 156 \\
\hline
\end{tabular}

Table 3 provides insights into the number of activities that address the sub-themes of the three learning domains of global citizenship. It indicates that the $23.7 \%$ of these activities offer discussions of themes related to local, national and global community issues while activities of local national and international system structures are really scarce $(0.6 \%)$. Table 3 also reveals that the three textbooks contain a statistically balanced number of activities that foster learners' sense of identity, belonging to local, national and international communities and respect for difference and diversity with percentages that reach $14 \%, 18 \%$ and $16.7 \%$, respectively. However, activities targeting the development of learners' engagement in collective, ethically responsible actions are not as abundant as the aforementioned ones.

Table 3: number of activities promoting different sub-themes of the learning domains

\begin{tabular}{|c|c|c|c|c|c|}
\hline Domains & Topics & Gateway 2 & Insights 2 & Ticket 2 & Total \\
\hline \multirow[t]{3}{*}{ Cognitive } & $\begin{array}{l}\text { Local, national \& global system } \\
\text { structures }\end{array}$ & 0 & 1 & 0 & $\begin{array}{l}1 \\
(0.6 \%)\end{array}$ \\
\hline & $\begin{array}{l}\text { Local, national \& global } \\
\text { communities issue }\end{array}$ & 17 & 10 & 10 & $\begin{array}{l}37 \\
(23.7 \%)\end{array}$ \\
\hline & Power dynamics & 2 & 3 & 3 & $\begin{array}{l}8 \\
(5.2 \%)\end{array}$ \\
\hline \multirow[t]{3}{*}{ Socio-emotional } & Different levels of identity & 6 & 8 & 8 & $\begin{array}{l}22 \\
(14 \%)\end{array}$ \\
\hline & $\begin{array}{l}\text { Belonging to different } \\
\text { communities }\end{array}$ & 8 & 9 & 11 & $\begin{array}{l}28 \\
(18 \%)\end{array}$ \\
\hline & $\begin{array}{l}\text { Difference \& respect for } \\
\text { diversity }\end{array}$ & 9 & 11 & 6 & $2(16.7 \%)$ \\
\hline \multirow[t]{3}{*}{ Behavioral } & $\begin{array}{l}\text { Actions taken individually or } \\
\text { collectively }\end{array}$ & 3 & 2 & 4 & $\begin{array}{l}9 \\
(5.7 \%)\end{array}$ \\
\hline & Ethically responsible behaviors & 5 & 5 & 4 & $\begin{array}{l}14 \\
(9 \%)\end{array}$ \\
\hline & Getting engaged \& taking action & 3 & 2 & 6 & $\begin{array}{l}11 \\
(7.1 \%)\end{array}$ \\
\hline Total & & 53 & 51 & 52 & $\begin{array}{l}156 \\
(100 \%)\end{array}$ \\
\hline
\end{tabular}

Table 3 provides a general account of the themes which are included in global citizenship activities throughout the three textbooks. It is concluded that textbooks present activities that usually promote learners' knowledge of various local, national and global issues (see Table 4 below) alongside fostering values of tolerance of difference, respect for diversity, reinforcing their sense of belonging to multiple layers of communities, and raising their awareness about plural identities. However, these textbooks do not allocate much room to activities that build learners' knowledge about how different system structures interact on the local, national and international levels and how power dynamics affect voice, influence, access to resources, decision-making 
and governance. More details about the nature of activities are provided in Table 4 below.

Table 4 reveals the themes discussed by those activities which promote different learning domains throughout the three textbooks. As far as the cognitive domain is concerned, Table 3 shows that Insights into English 2 is the only textbook which discusses the structure of the Moroccan parliament as indicated previously in Table 1. It is also observed that the three textbooks provide information about issues related to local, national and global communities such as brain drain, environmental problems, culture shock, stereotypes, racism and unemployment. Table 4 demonstrates that the three textbooks offer insights into how power dynamics influence various communities through NGOs, international organizations, associations and governmental institutions.

Table 4 indicates that the three textbooks include activities that promote the sociocultural domain. It reveals that they present a plethora of activities which raise learners' awareness of various levels of identity including gender, social, national and racial identity in ways that promote peaceful coexistence among people from different groups. The socio-emotional domain is further fostered by including activities which encourage learners to consider themselves as potentially belonging to different communities through discussions of immigration, brain drain, tourism all of which themes promote learners' understanding of how different groups, communities and countries are interconnected. The table additionally reveals that these textbooks boost learners respect for diversity by offering discussions that compare and contrast foreign and local perspectives, practices and products in ways that develop positive attitudes towards diverse groups, opinions and perspectives.

Table 4 displays evidence that the three textbooks include activities that enhance learners' global citizenship behaviors. It indicates that they contain activities that encourage learners to take action either individually or collectively through themes of community service, role of associations and NGOs and youth engagement in sociopolitical issues. It is also noticed that these textbooks provide discussions of themes that raise learners' awareness of ethically responsible behaviors aiming at promoting social justice through topics related to reacting against gender inequality, discrimination, racism, marginalization and oppression. The three textbooks offer learners opportunities of getting engaged and taking action against glocal issues by writing emails to officials suggesting solutions to these problems, or taking action through voluntary work and community service in their immediate environment against problems of environment, illiteracy, anti-smoking campaigns and health issues. 
Table 4: Themes representing the learning domains in the textbooks

\begin{tabular}{ll}
\hline Domains & Themes \\
\hline Cognitive & Moroccan Parliament structure \\
& Brain drain, environment, culture shock, stereotypes, racism, unemployment \\
& NGOs, international organizations, associations, governmental institutions, cooperatives \\
Gender, ethnic, national, racial identities & Immigration, brain drain, tourism \\
& Compare different cultures, promote equality despite difference, \\
& Community service, NGOs, Associations, youth engagement \\
Behavioral & Promote social justice, fight discrimination, tolerance \\
& Brain drain, environment, voluntary work, political activism \\
\hline
\end{tabular}

\section{Discussion}

In response to the first research question, the three textbooks present a sufficient number of activities that are capable of developing the various knowledges, skills, values and behavior of global citizenship, as claimed by Byram (2011) and Weninger and Kiss (2013). With an average rate of 5 activities per unit, these textbooks succeed in offering opportunities for fostering learners' global citizenship awareness. In line with Byram (2011) and Weninger and Kiss (2013), it is observed that these activities are mostly integrated within main language courses including reading, listening, writing, speaking and project-works. The issue of whether these activities are appropriately used remains the choice and responsibility of the teachers as clearly stated by EL Karfa (2007).

With regard to the second research question, the findings indicate that the three textbooks contain a diversified set of activities and themes that develop the different global citizenship domains of learning. Similar to Basarir (2017) and Erfani (2013), the three textbooks offer numerous opportunities where learners can learn about a plethora of themes that develop their global citizenship knowledges, skills, values and behaviors. Another point in favor of these textbooks is that they have succeeded in incorporating these themes within activities under the major lessons of reading, listening, writing, speaking and project works. Most global citizenship activities included within reading and listening merely present facts and information about topics included in Table 3. Those activities integrated in writing and speaking activities usually ask learners to plan or suggest actions to be taken either to solve or promote some aspects of global citizenship, but they rarely ask them to reflect critically about these aspects. Project works often require learners to engage in immediate out-of-the-classroom action in form of extracurricular activities that enhance learners' sense of responsibility, belonging and civic engagement.

However, contrary to De La Caba and Atxurra (2006) and Erfani (2012), popular global citizenship theme of democracy, human rights, global health issues and conflict resolution are to a great extent not addressed in Moroccan $2^{\text {nd }}$ year Baccalaureate 
textbooks. Also, it is noted that the ways in which these themes are presented does not allow for meeting the overall objectives set for upper-secondary level by UNESCO (2015). The activities mainly provide learners with knowledges, skills, values and behaviors in ways that are superficial and factual. As previously indicated by De La Caba (2013), most activities included in the Moroccan ELT textbooks we investigated do not present contents that contribute to developing global citizenship values. They do not offer enough opportunities for learners' to critically' discover, analyze, question, assess and evaluate the efficiency, appropriateness, relevance and suitability of knowledges, skills, values and behaviors to socio-economic and cultural environment of these learners. Reinforcing Zhu's (2013) findings, it is noticed that the themes included in these textbooks target more national and international issues than local ones, except at the level of behavior where the moto 'think globally act locally' is applied (see for example Hammani, Ahssen, \& Tansaoui, 2007: 124; Hassim, Blibil \& Rasmy, 2007: 117; Najib \& El Haddad, 2007: 122).

In short, the three textbooks testify for the fact that Global Citizenship Education is at its initial stages in Morocco as already stated by LSCE (2017). They have set a good example to follow by textbooks from other subjects so that global citizenship will be integrated across the curriculum as a major cross curricular theme (see UNESCO, 2015). Yet, as El Karfa (2007) noted, careful selection, organization and illustration of the content is highly required.

\section{Conclusions}

This paper investigated the extent to which three Moroccan ELT textbooks currently used in public high schools present activities that develop learners' sense of belonging to global and local communities and provide them with skills, knowledges and behaviors that would make them good citizens of the world. The research was informed by the theoretical framework of the Standards-Based Approach and UNESCO's (2015) global citizenship learning domains. It adopts a convergent parallel mixed-methods design and uses content analysis as a data analysis method which combines both qualitative and quantitative techniques. The materials included three textbooks: Gateway to English 2, Insights into English 2 and Ticket to English 2. The findings demonstrate that although the three textbooks actually provide a number of activities that promote aspects of citizenship, there is still room for improving learners' awareness of various global issues including democracy, human rights and conflict resolution. Other problems related to developing learners' critical perspective towards global citizenship themes in reading texts, speaking, listening and writing activities, writing and project works are identified.

In light of the findings, this study concludes with a set of implications addressed to textbook designers. To start with, textbook designers need to include activities that promote understanding of how local, national and global political, economic and social structures work, interact and influence our communities. Such activities include

\footnotetext{
${ }^{\dagger}$ My emphasis
} 
reading, listening, speaking, writing and project work activities which encourage learners to use their critical thinking to identify ways in which individual actions towards glocal issues may have global consequences and vice-versa. One major point that could be emphasized throughout these activities is questioning the utility of global, national and local systems, laws and constitutions in promoting democracy by comparing, contrasting and evaluating excerpts of official documents. Textbook designers are expected to move beyond the mere superficial presentation of facts and information about global citizenship issues to creating learning situations where learners are required to critically analyze, interpret and evaluate causes, consequences and possible practical solutions for global phenomena. Textbook designers are also encouraged to design activities that allow for discussing local issues that have national and global dimensions and inspire students to plan and take individual or collective action by providing examples of successful people who take local action against global problems. It is of crucial importance that students are made aware that individual small actions on the local scale can certainly make a difference on the national and global scale as well.

\section{Acknowledgements}

I would like to thank Dr. Bouchaib Benzehaf for proofreading the final version of the paper.

\section{The Conflict of Interest Statement}

In line with the statement of Committee on Publication Ethics (COPE), I hereby declare that we had no conflicting interests regarding any parties of this study.

\section{References}

Ait Bouzid, H (2016). Promoting values of religious tolerance through Moroccan ELT textbooks. Asian TEFL, 1(2), 89-100.

Ait Bouzid, H., Erguig, R., \& Yeou, M. (2016). Towards a reflective textbook evaluation model. EFL Journal, 1(3), 219-233.

American Council on the Teaching of Foreign Languages. (1996). Standards for Foreign Language Learning: Preparing for the 21st Century. Alexandria: Author.

Basarir, F. (2017). Examining the Perceptions of English Instructors Regarding the Incorporation of Global Citizenship Education into ELT. International Journal of Languages' Education and Teaching, 5(4), 409-425.

Byram, M. (2011). Intercultural citizenship from an internationalist perspective. Journal of the NUS Teaching Academy, 1(1), 10-20.

Byram, M. (2003). Teaching languages for democratic citizenship in Europe and beyond. In K, Brown, \& M, Brown (Eds.). Reflections on citizenship in a multilingual world, 15-24. London: Centre for Information on Language Teaching and Research.

Cates, K. A. (2009). Teaching for a better world: Global issues and language education. Human Rights Education in Asian Schools, 5, 41-52.

Creswell, J. W. (2012). Educational research: Planning, conducting and evaluating quantitative and qualitative research. Boston: Pearson Education Inc. 
Cunningsworth, A. (1995). Choosing your Coursebook. Oxford: Heinemann.

De La Caba, M. \& Atxurra, R. L. (2006). Democratic citizenship in textbooks in Spanish primary curriculum. Journal of Curriculum Studies, 38(2), 205-228.

Diaz, L. (2016). Citizenship education and the EFL standards: A critical reflection. Profile: Issues in teachers' professional development, 19(1), 155-168.

El Karfa, A. (2007). Open classroom communication and the learning of citizenship. English Teaching Forum, 4, 38-42.

Erfani, S. M. (2012). The rationale for introducing "global issues" in English textbook development. Theory and Practice in Language Studies, 2(11), 2412-2416.

Guilherme, M. (2002). Critical citizens for an intercultural world: Foreign language education as cultural politics. Clevedon: Multilingual Matters.

Hammani, M., Ahssen, S., \& Tansaoui, L. (2007). Ticket 2 English. Casablanca: D.I.O. El Hadita.

Hassim, M., Blibil, M., \& Rasmy, A. (2007). Gateway to English 2. Rabat: Nadia Edition.

Kerr, D. (1999). Citizenship education in the curriculum: an international review. The School Field, 10(3), 7-32.

Krippendorff, K. (2013). Content analysis: An introduction to its methodology. CA: SAGE Publications, Inc.

Life Skills and Citizenship Education. (2017). Reimagining life skills and citizenship education in MENA. Amman: UNICEF.

Litz, D. (2005). Textbook evaluation and EFL management: a South Korean case study. Asian EFL Journal, 48, 1-53.

Ministry of National Education. (2007). English Language Guidelines for Secondary Schools: Common Core, first year, and second year baccalaureate. Rabat: Author.

Najib, M., \& El Haddad, E. (2007). Insights into English 2. Rabat: Al Massar Edition.

O'Brien, M., \& Parry, L. (2002). From national identity to global citizenship: challenges for citizenship education in Australia. The International Journal of Social Education, 17(1), 3140.

OXFAM. (2015). English and global citizenship. Retrieved from https://www.oxfam.org.uk/education/resources/english-and-global-citizenship

Pederson, P. \& Cogan, J. (2002). Civics education, pedagogy, and assessment in the Pacific Rim:Six cases. The International Journal of Social Education, 17(1), 16-30.

UNESCO. (2015). Global citizenship education: Topics and learning objectives. Paris: Author.

Weninger, C. \& Kiss, T. (2013). Culture in English as a Foreign Language (EFL) Textbooks: A Semiotic Approach. TESOL Quarterly, 47(4), 694-716.

Yakovchuk, N. (2004). Global issues and global values in foreign language education: Selection and awareness-raising. ELTED, 8, 28-47.

Zhu, J. (2013). Citizenship education and foreign language teaching: Deconstructing the concept of good citizenship embedded in foreign language curricula in China and America. Utah: Utah State University.

\section{Copyrights}

Copyright for this article is retained by the author(s), with first publication rights granted to the Journal.

This is an open-access article distributed under the terms and conditions of the Creative Commons Attribution license (CC BY-NC-ND) (http://creativecommons.org/licenses/by-nc-nd/4.0/). 